\title{
Developing Civic Responsibilities in a Large Lecture through Debates*
}

\author{
Emily K. Lynch \\ Department of Political Science \\ University of Rhode Island \\ emilylynch@uri.edu
}

\begin{abstract}
How do political scientists encourage students in a large lecture to develop civic responsibilities? The Introduction to American Politics course at The University of Rhode Island fulfills a general education requirement learning outcome to "develop and engage in civic knowledge and responsibilities." One way to foster political responsibilities is to promote debate in the classroom (e.g., Campbell 2008; Oros 2007). It can be a challenge to encourage students to strengthen their civic skills through debate in a large classroom setting where nearly 400 students are divided into two large lectures. I examine three key areas to assess the effectiveness of debates in the classroom as a tool to increase student exposure to and engagement in political discussion, including: 1) the importance of discussing debate topics in the lectures and recitations, 2) the use of technology to encourage debate participation, and 3) the development of proper assessments to gauge whether students have critically analyzed the debate topics. Given the recent high levels of partisan animosity (Pew Research Center 2014), it is imperative that college students learn to respectfully debate important political issues.
\end{abstract}

*Working paper prepared for presentation at the American Political Science Association's Teaching and Learning Conference, February 7-9, 2020, Albuquerque, New Mexico. This is a first draft of a research plan that may take several years to complete - please do not cite or distribute without permission from the author. 
In the current era of political polarization, many people are completely avoiding attitudediscrepant views, based on the media they choose to view (Bennett \& Iyengar 2008) and in faceto-face interactions (Mutz 2006). Political polarization and the lack of effective political debate are exacerbated by the widespread use of the internet where individuals who participate in uncivil online discussion have lower expectations about public deliberation (Hwang, Kim, \& Huh 2014). Given the negative political climate, it is imperative that students graduate college with the political knowledge and critical thinking skills needed to successfully engage with others about political issues. When classrooms have an open climate where students can discuss divisive issues, students learn to appreciate political conflict (Campbell 2008).

How do political scientists encourage students in a large lecture to develop civic responsibilities like the ability to debate and discuss politics with others? One avenue would be to promote in-class activities that do just that - give students the opportunity to debate divisive topics that encourage students to engage with multiple arguments. In-class debates can increase both political knowledge and skills to critically evaluate ideas, arguments, and points of view. I find preliminary evidence that students overwhelmingly agreed that the debates improved their civic engagement skills, as defined by levels of political knowledge, critical thinking skills, and confidence in discussing political issues. I discuss the implications of these findings at the end of the paper.

I examine three key areas to assess the effectiveness of debates in the classroom as a tool to increase student exposure to and engagement in political discussion, including: 1) the importance of discussing debate topics in the lectures and recitations, 2) the use of technology to encourage debate participation, and 3) the development of proper assessments to gauge whether 
students have critically analyzed the debate topics. This is an exploratory paper that I plan to build upon as I continue to teach large lectures for Introduction to American Politics.

\section{Literature review}

Myriad research find that debates promote civic skills that are integral to serving as an engaged citizen. An open classroom climate that uses debates to engage with the material can lead to better civic knowledge and likelihood to vote (Campbell 2008). Debates can provide opportunities for students to gain "a deeper understanding of (and empathy for) the ethical complexities of political issues" (Lantis 2004). The benefits of in-class debates are not restricted to the United States. In a study about using debates in secondary schools in multiple countries, the results show similar patterns of positive student learning across countries, including better understanding of controversial issues, ability to articulate their views, and greater confidence in speaking about the issues (Avery, Levy, \& Simmons 2013).

Assessments of the effectiveness of debates have used student feedback, either through anecdotes or surveys. Debates enhance various certain civic engagement skills in varying degrees. Debates improve political skills and democratic values, and the significance of this improvement is dependent on whether the debate format is more structured or informal (Abernathy and Forestal 2019). Policy debates can increase students' level of information literacy and critical thinking skills (Leek 2016). Evidence suggests that use of debates increased students' level of knowledge about course topics (Keller, Whittaker, \& Burke 2001). However, other scholars suggest that students are more likely to gain knowledge of course topics in standard lectures than debates, and debates are better at increasing students' level of comprehension, application, and critical evaluation (Omelicheva \& Avdeyeva 2008). One way to 
encourage the growth in multiple civic engagement skills is to adopt several different forms of teaching methods including both debates and lectures.

Debates have been studied in a variety of college classroom settings. Not only have debates been used in political science courses (e.g., Abernathy \& Forestal 2019), but debates have been beneficial for a wide range of programs, such as occupational therapy where competing service delivery models can be debated for case studies (Griswold 1999). Even online classes have adopted debates as a beneficial way to strengthen critical thinking skills (Park, Kier, \& Jugdev 2011; Schaeffer, McGrady, Bhargava, \& Engel 2002). While much of the previous research focuses on the impact of debates in a variety of classes - be it online or inperson, there is less research on debates in a large classroom setting. Oros $(2007,309)$ mentions that debates "simply might not be feasible for large lecture classes" but acknowledges that debates can occur in smaller discussion section with a teaching assistant. Students may struggle in large lectures because there are large variations in motivation and engagement, measured by intrinsic value, self-efficacy, self-regulation, and student perceptions about how the course is taught (Kim, Park, Huynh, \& Schuermann 2017). One remedy to promote more active learning is to include more images and less text large lecture slides (Roberts 2018), but a thorough discussion of debates in large lectures is lacking in the political science education literature. More research is needed to explain the best practices for integrating debates into large lectures and recitations.

\section{The Debate Assignment}

The debates examined in this study were from an Introduction to American Politics course at a public institution in New England. This land grant university has over 18,000 
students. $54 \%$ of students are Rhode Island residents, $20 \%$ of newly admitted students are students of color, and $57 \%$ are women. Undergraduate students signed up for one of two sections of the Introduction to American Politics course. The Introduction to American Politics course counts as a general education course that is meant to provide a breadth of knowledge about a wide array of topics beyond a student's major. This course meets two general education learning outcomes that students must fulfill for general education requirements, including "understand theories and methods of the social and behavioral sciences" and "develop and engage in civic knowledge and responsibilities."

Course enrollment was high due to its designation as a general education course. Over 380 students were enrolled in the two sections (Section 1: 217 students; Section 2: 167 students) in Fall 2019. Most of the students were not political science majors. There were less than 35 political science majors per class (11.5\% in Section 1; $18.6 \%$ in Section 2). Roughly half of the students in each section were freshmen (48.8\% in Section 1; 55.7\% in Section 2), and about a third of students were sophomores (34.6\% in Section 1; 32.9\% in Section 2). A small percentage of students were juniors (12.9\% in Section 1; 9\% in Section 2) and seniors (3.7\% in Section 1; $2.4 \%$ in Section 2).

It can be a challenge to encourage students to strengthen their civic skills through debate in a large classroom setting where nearly 400 students are divided into two large lectures, so debates were conducted in the recitations that were run by the TAs. Within these two course sections, students signed up for one of 16 recitations, with a class size ranging from 22 to 26 students. The recitations are designed to provide students with an in-depth examination of the material covered in the readings and lecture, a chance to ask questions, engage in a formal 
debate, as well as an opportunity to review key concepts. Five teaching assistants (TAs) taught the recitations in Fall 2019. The TAs were graduate students completing their M.A. in International Relations. Three of the graduate students had already served as a TA for American Politics and International Relations courses in the previous year, and two graduate students did not have any teaching experience. Each TA was given the same instructions and grading rubric for the debate. The recitation counted for $20 \%$ of the final grade. Half of the recitation grade consisted of the debate presentation, which took place during recitations. The other half of the recitation grade consisted of recitation participation, including attendance and participating in discussions, with an emphasis on participating in debate discussions during the recitation.

Students signed up for a debate topic during the first week of recitation and TAs explained the debate assignment during recitation. Each debate topic reflected the chapter reading for the week (see Table 1 for topic examples). Some of the debate questions came from William Miller's Taking Sides textbook (2015).

Table 1. Examples of debate questions and topics.

\begin{tabular}{|l|l|}
\hline Debate Question & Topic \\
\hline $\begin{array}{l}\text { Should the U.S. Be More Restrictive of } \\
\text { Gun Ownership? }\end{array}$ & Civil Liberties \\
\hline $\begin{array}{l}\text { Has the current media environment } \\
\text { become an echo chamber? }\end{array}$ & $\begin{array}{l}\text { Political Culture and } \\
\text { Socialization }\end{array}$ \\
\hline $\begin{array}{l}\text { Is divided government better than one- } \\
\text { party control? }\end{array}$ & Political Parties \\
\hline $\begin{array}{l}\text { Should the Courts seek the "original } \\
\text { meaning" of the Constitution? }\end{array}$ & The Courts \\
\hline
\end{tabular}

Instructions included several components, including (1) general guidelines for the debate (no personal attacks, no correct answers), (2) an overview of the importance of this assignment (enhance critical thinking skills and gaining tolerance for different views), (3) an outline of the 
main components in a debate presentation (argument and evidence, rebuttal, and closing statement), (4) the debate procedure. The debate procedure consisted of time limitations for each side during each of the debate sections ( 5 minutes per side for stating argument and evidence, 2 minutes per side for rebuttal, and 2 minutes per side for closing statement). The final part of the debate consisted of a 5-10-minute class discussion where presenters were responsible for answering any questions the students may have about their presentation.

Student grades were based on content and presentation style (each worth $50 \%$ of the grade). The following components were assessed in the content section (50\% of grade): 1) strength of empirical evidence, 2) discussed evidence beyond textbook material, 3) discussed weakness of the opposite side, and 4) mentioned sources during debate and turned in a reference page. The presentation style consisted of 1) organization, 2) interesting presentation, and 3) made effective use of their time. The grading rubric is included in the appendix.

Grading is one area where I would like to continue examining the appropriate criteria to fully assess whether students are strengthening their political knowledge and critical thinking skills. Although I required students to turn in a reference page, I did not require students to turn in a short paper with the presentation because I wanted students to focus on their in-class presentation. The next time I teach the course I will reconsider the required components of this assignment by researching whether writing a short paper along with the presentation would be a more effective way for students to strengthen their civic engagement skills.

In the large lectures, students were required to use TopHat, a classroom response system, that gives feedback in real-time. At the beginning of each week, I asked students to answer an opinion question about the debate. The following week, I asked the same question to see if there 
were any major changes in the aggregate opinions. For example, for the debate question, "Does a bigger national government make a better government," the majority of students in both sections responded "no" before and after the debate. One noticeable change was that less students chose "not sure" after the debate, decreasing the size of this group by about half the size of the original "not sure" group (section 1 "not sure": before (22\%); after (10\%); section 2 "not sure": before $(15 \%)$; after (6\%)). In lecture, I elaborated on concepts and issues related to the debate topic, and the students' required reading could have influenced their views, so I am unable to attribute all changes in opinion directly to the debate activity. Although I tried to connect debates to lecture material so it would help students have a better understanding of the debate topic, I was unsure the extent to which I should explicitly make these connections since I wanted the students to be able to do this on their own. In the future, I will experiment by giving students more explicit information at the beginning of the semester with the first couple debates, and then at the end of the semester I will encourage students to independently make the connections between lecture and recitation debates. Perhaps a useful way to guide students in their learning is to give specific discussion questions in the lectures related to the debate topic.

\section{Student Feedback}

At the beginning of the final class of the semester, I asked students to critically evaluate the effectiveness of the debates. I asked students the following question, "To what extent do you agree with the following statement," and students responded to the following three statements:

- Participating in recitation debates improved my level of political knowledge.

- Participating in debates increased my confidence in discussing political issues.

- Participating in debates strengthened my critical thinking skills. 
Students were given 30 seconds to anonymously respond to each question using TopHat. Table 2 includes the evaluations for each section. It is important to note that many students did not respond to this essay. I had a 52-58\% response rate for Section 1 (217 students) and 49-55\% response rate for Section 2 (167 students).

Table 2. Student Evaluations of Debates

\begin{tabular}{lcccc}
\hline \hline Section 1 & & & & \\
\hline & Agree & Disagree & Neutral & Total \\
\hline Improved level of political knowledge & $85.8 \%$ & $9.7 \%$ & $4.4 \%$ & 113 \\
$\begin{array}{l}\text { Confidence in discussing political } \\
\text { issues }\end{array}$ & $79.2 \%$ & $8 \%$ & $12.8 \%$ & 125 \\
Strengthened critical thinking skills & $72.2 \%$ & $17.5 \%$ & $10.3 \%$ & 126 \\
\hline & & & & \\
Section 2 & & & & \\
\hline Improved level of political knowledge & $85.4 \%$ & $9.8 \%$ & $4.9 \%$ & 82 \\
Confidence in discussing political & & & & \\
issues & $78.4 \%$ & $13.6 \%$ & $8.0 \%$ & 88 \\
Strengthened critical thinking skills & $82.6 \%$ & $9.8 \%$ & $7.6 \%$ & 92 \\
\hline
\end{tabular}

The results of these self-assessments were very positive. An overwhelming majority of students in each section agreed that the debates improved their level of political knowledge, gave them more confidence in discussing political issues, and strengthened their critical thinking skills. An interesting finding is that most students agreed that the debates improved their level of political knowledge, which suggests that debates, despite the conflicting evidence in the literature, can improve both political knowledge and critical thinking skills. I was surprised by the high percentage of students $(17.5 \%)$ in the first section's results that disagreed that the debates strengthened their critical thinking skills. One caveat is the number of students in the first section who answered these questions increased by 13 students from the first question to the 
third question. These handful of students may have skewed the results since they might not have been attentive listeners during the lecture and, in general, less interested in the course.

The results from the "confidence in discussing political issues" question show that there was a large percentage of "neutral" respondents (12.8\% in Section 1; $8 \%$ in Section 2). For the second section, the percentage of "agree" respondents for this question was the lowest out of the three questions (78.4\%). A better way to assess growth over the semester would be to ask these questions at the beginning of the semester and compare them to responses to same questions at the end of semester. More measures are needed to fully examine which teaching tools work best to strengthen students' confidence in discussing politics. One option might be to devote five minutes each week in the large lectures to a student discussion of the debate topic.

Overall, the results of the student assessments of the debate activity was a positive sign that students found this activity to be an effective way to learn the class material. The results also stimulate new questions and ideas about debate formats in large lectures and better ways to connect the large lecture to the recitation debates, which I hope to examine in future analyses.

\section{Discussion}

Active learning allows students the opportunity to fully engage with class concepts, ideas, theories, and arguments. When debates are used as a type of active learning, students are no longer passive listeners in lectures and recitations but involved participants in the learning process. Furthermore, using debates in the classroom can foster political responsibilities (e.g., Campbell 2008; Oros 2007), which is arguably an essential learning outcome for all political science courses. My initial examination of using debates in a large lecture setting suggests that debates can be used when the actual debates are conducted in the associated recitations and 
important concepts and ideas related to the debate as well as aggregate student opinion on the debate topic can be emphasized and discussed in the large lecture.

There may be potential drawbacks with the use of debates in the classroom. First and foremost, instructors must consider whether students are actually learning specific concepts about the course material through their debates, or if students, who are mostly non-majors, may struggle with learning the course material through the debate process because of a lack of familiarity with the course concepts. Additionally, instructors should carefully assess whether students are gaining important political knowledge about how our government works in recitations through the debates, or if recitation time is better spent covering specific course material that students were struggling with or giving new examples not discussed in the large lecture. An alternate option for recitations is to use the class time for quizzes instead of debates. Another important consideration is the amount of time spent during the large lecture that is dedicated to discussing the debate to make connections with the recitation debates. The more time instructors devote in lecture to discuss debates, the less time instructors have to talk about important lecture material that is unrelated to the debate topic. This underscores the importance of the debate topic - if the debate topic is broad enough, then instructors will have the ability to make lots of connections to much of the course material.

Systematic testing of my hypothesis with quantitative data is not included in this first draft, but I hope to use this paper as a springboard for future quantitative studies using survey methods to examine how to best teach political science in large lectures. As I continue teaching large introductory political science courses, I would like to further analyze the effectiveness of debates by considering the following: (1) revisit the format of debates, (2) evaluate whether 
grades should be solely on the presentation or a critical analysis paper should be required, and (3) assess whether less debates with larger teams would be more appropriate.

I would like to link my future observations and findings with the political communication and political psychology literature on party polarization, selective exposure, and public deliberation. These rich political science subfields are optimal areas that intersect with research on political science education. People are avoiding political discussion, especially young adults, where only $12 \%$ of young adults (18-34) discuss politics, versus 33\% of older adults (55+) (Gallup 2019). One reason for not participating in politics like discussing politics, contacting an elected official, and voting is that some people are conflict avoidant, but one way to overcome this psychological factor is through higher education, which "may train people to tolerate and expect intellectual disagreement" (Ulbig and Funk 1999, 277). 


\section{References}

Abernathy, Claire and Jennifer Forestal. 2019. "The Use of Debates in Political Science Courses." Journal of Political Science Education.

Avery, Patricia G., Sara A. Levy, and Annette M. M. Simmons. 2013. “Deliberating Controversial Public Issues as Part of Civic Education.” The Social Studies 104(3):105 114.

Bennett, W. Lance, \& Iyengar, Shanto. 2008. “A new era of minimal effects? The changing foundations of political communication." Journal of Communication 58(4): 707-731.

Campbell, David E. 2008. "Voice in the Classroom: How an Open Classroom Climate Fosters Political Engagement Among Adolescents." Political Behavior 30: 437-454.

Griswold, Lou Ann S. 2000. "Debate as a Teaching Strategy.” The American Journal of Occupational Therapy 54 (4): 427-428.

Hwang, Hynseo, Youngju Kim and Catherine U. Huh. 2014. "Seeing is Believing: Effects of Uncivil Online Debate on Political Polarization and Expectations of Deliberation. ” Journal of Broadcasting \& Electronic Media 58(4): 621- 633.

Jones, Jeffrey. 2019. Americans converse more about family matters than politics. Gallup. Retrieved from https://news.gallup.com/poll/262166/americans-converse-family-matters politics.aspx.

Keller, Thomas E., James K. Whittaker and Tracey K. Burke. 2001.”Student Debates in Policy Courses." Journal of Social Work Education 37(2), 343-355.

Kim, ChanMin, Seung Won Park, Niem Huynh \& Ryan Thomas Schuermann. 2017. "University students' motivation, engagement and performance in a large lecture-format general education course." Journal of Further and Higher Education 41(2): 201-214. 
Lantis, Jeffrey S. 2004. "Ethics and Foreign Policy: Structured Debates for the International Studies Classroom.” International Studies Perspectives 5: 117-133.

Leek, Danielle R. 2016. "Policy debate pedagogy: a complementary strategy for civic and political engagement through service-learning." Communication Education 65 (4): 397 408.

Miller, William. J. (2015). Taking Sides: Clashing Views on Political Issues (19 th ed.). New York: McGraw-Hill Education.

Mutz, Diana. C. 2006. Hearing the other side: Deliberative vs. participatory democracy. New York: Cambridge University Press.

Omelicheva, Mariya Y., and Olga Avdeyeva. 2008. "Teaching with Lecture or Debate? Testing the Effectiveness of Traditional versus Active Learning Methods of Instruction.” PS: Political Science and Politics 41(3):603-607.

Oros, Andrew L. 2007. "Let's Debate: Active Learning Encourages Student Participation and Critical Thinking." Journal of Political Science Education 3(3):293-311.

Park, Caroline, Cheryl Kier, and Kam Jugdev.2011. "Debate as a teaching strategy in online education: a case study." Canadian Journal of Learning and Technology 37(3): 1-17.

Roberts, David. 2018. “Active Learning Precursors in Multidisciplinary Large Lectures: A Longitudinal Trial on the Effect of Imagery in Higher Education Lectures." College Teaching, 66(4): 199-210. DOI: 10.1080/87567555.2018.1486802

Schaeffer, Evonne L.; Jennifer A. McGrady, Tina Bhargava, and Claudia Engel. 2002. "Online Debate to Encourage Peer Interactions in the Large Lecture Setting: Coding and Analysis of Forum Activity." Paper presented at the Annual Meeting of the American 
Educational Research Association (New Orleans, LA, April 1-5, 2002). Retrieved from https://files.eric.ed.gov/fulltext/ED465344.pdf.

Ulbig, Stacy G. and Carolyn L. Funk. 1999. "Conflict avoidance and political participation.” Political Behavior 21(3): 265-282. 


\section{Appendix}

\section{Grading Rubric for Debate Presentation \\ (100 points $/ 50 \%$ of Recitation Grade)}

The questions will be graded using a scale of 0 to $10(20)$, with $0=$ poor and $10(20)=$ excellent, for a total of 100 points.

\section{Content}

1. Did the student use strong empirical evidence to defend his or her points? 20pt.

2. Did the student discuss evidence beyond what was presented in the textbook? 10pt.

3. Did the student discuss the weak points of the opposite side? 10pt.

4. Were all sources of facts and examples mentioned in the debate and did the student turn in a reference page with at least two outside sources? 10pt.

Presentation Style

1. Was the presentation well organized? 20pt.

2. Did the student make the presentation interesting to the class? $10 p t$.

3. Did the student make effective use of their time for the initial argument, response, and closing statement? 20pt. 